\title{
AIDS knowledge and educational needs of technical university students in Turkey
}

\author{
Mehmet Ungan ${ }^{\mathrm{a}}$, Hakan Yaman ${ }^{\mathrm{b}, *}$ \\ ${ }^{a}$ Medical Center, Middle East Technical University, Ankara, Turkey \\ ${ }^{\mathrm{b}}$ Department of Family Medicine, Akdeniz, University, Medical School, Antalya, Turkey
}

Received 15 February 2002; received in revised form 10 June 2002; accepted 8 September 2002

\begin{abstract}
AIDS is a main health problem of the recent century and is now considered a very important cause for mortality and morbidity among young people. The aim of this research is to determine the Turkish university students knowledge, sexual risk behavior, attitude towards AIDS and educational needs concerning AIDS. A cross-sectional exploratory design is utilized in this study. One thousand four hundred and twentyseven university new registrants from the Middle East Technical University participated and answered a 32-item self-administered questionnaire. The questionnaire addressed sociodemographics, sexual risk behavior, self-assessed knowledge on HIV transmission and AIDS, attitudes towards AIDS infection and AIDS patient, source of information and need for AIDS course. The response rate was $84 \%$. Two hundred and seventy-one (19\%) participants had sexual intercourse. Eighty-one (30\%) participants reported condom use during the last encounter. Seven hundred and twenty-four (51\%) stated they knew "very much" about AIDS. Students of faculty of engineering $(n=384$, $69 \%)$, economic and administrative sciences $(n=115,55 \%)$, and architecture $(n=42,52 \%)$ declared they knew "very much" on AIDS and had a higher frequency as the students from the faculty of arts and sciences $(n=119,43 \%)$ and education $(n=64,40 \%)$. Television was reported as the major source of information about AIDS $(n=871,61 \%)$. Students in faculty of education had lower scores than others $(P=0.01)$. Almost all students stated that there should be a course on AIDS in their curriculum. Educational and medical institutions are the minor information sources for students at universities. Therefore, schools have to integrate new courses on AIDS and sexual health in their curricula, physicians caring for these students have to take more time for health education.
\end{abstract}

(C) 2002 Elsevier Science Ireland Ltd. All rights reserved.

Keywords: AIDS; Knowledge; Perception; Adolescents; Students; Turkey

\section{Introduction}

Human immunodeficiency virus (HIV) and acquired immune deficiency syndrome (AIDS) are among the most complex health problems of the 21 st century. It was responsible for an estimated 11.3 million deaths since the pandemic began. New tables prepared by the World Health Organization (WHO) show that of 33.6 million people infected with the HIV virus, more than $90 \%$ occur in developing countries, where the HIV virus is still relatively unknown among people. WHO reports also that about more than $45 \%$ of all new infections occur in people aged 15-24 years [1].

In Turkey, the first AIDS case was diagnosed in 1985. History of AIDS started with two patients, and AIDS cases increased each year: 34 new cases in 1990, 91 new cases in

\footnotetext{
* Corresponding author. Çelebiler mh. 119.cd.no. 11/7, 32040 Isparta, Turkey. Tel.: +90-246-211-2317; fax: +90-246-237-0240.

E-mail address: hyaman@gmx.net (H. Yaman).
}

1995, and 119 new cases in 1999. According to December 1999 statistics of the Turkish Ministry of Health the total number of HIV positive patients is 983 [2]. These numbers, however, are only the official numbers of the Ministry of Health. It is known, infectious disease increase in number of patients geometrically, so based on the two cases in 1985, the actual number of the patients in 1999 is calculated about 17000. According to the information of the Ministry of Health, AIDS is considered to be in its beginning phase, but based on the calculation above; AIDS seems to become a health problem for Turkey [3].

The earliest initiative in prevention of HIV/AIDS infection came from the Ministry of Health after the first case was diagnosed. Non-governmental organizations like the Turkish Family Planning Association, the Association of AIDS Prevention, the Association of AIDS War, the Foundation of Improving the Human Resources, and Hacettepe University AIDS Treatment and Research Center have been carrying out AIDS prevention and education activities. 
Some have reached their goals but some are far from being effective [4].

Sexual education of adolescents within the Turkish family is poor and talking about sexuality is possible rarely with their intimate friends in great secrecy. As a result sexual information for young people about sexual relationship and marriage are still ineffective [5]. Since students are among the most vulnerable groups in the society and students are commonly experimental, the assessment of knowledge of students about AIDS is important in planning appropriate preventive measures [6].

Health education and prevention remain the main health care priorities in AIDS prevention, since AIDS is still an non-curable disease. The importance of adequate knowledge on AIDS in relation to infection control is evident. It can be supposed that accurate knowledge about AIDS will reduce risk behavior. We can expect adolescents with greater knowledge to avoid high risk behavior, though there is no guarantee in this aspect [7].

Little has been written on knowledge assessment of HIV/ AIDS among young Turkish people living in Turkey. Therefore, the aim of this study is to evaluate university students' high risk behavior and knowledge of university students about AIDS, to assess needs for sexual education and to discover sources of information about AIDS for the university students.

\section{Respondents and methods}

\subsection{Study sample}

The target population of this study were new Turkish students enrolled in Middle East Technical University (METU) in Ankara, Turkey in September 2000. The questionnaire was conducted prior medical registration and was facilitated by the assistance of officers at the health center. Students were informed about the general objectives of the research and were asked not to write their names on the questionnaire in order to ensure the confidentiality of the information they will provide. Voluntary participants were asked for a written consent for participation in to this study. One thousand six hundred and ninety-three (66\%) of 2575 Turkish students were willing to participate in this study. One thousand four hundred and twenty-seven (84\%) of 1693 questionnaires were duly complete and returned.

\subsection{Questionnaire}

The questionnaire had 32 items and was designed in lay Turkish. The questionnaire was composed of three parts: (1) student's personal data; (2) statements on student's knowledge; (3) evaluation of sexual risk behavior, self-assessed knowledge on HIV transmission and AIDS, source of information and need for AIDS course. Personal data included student's sex, age, and type of faculty. The second part consisted of 20-item scale on AIDS knowledge. This scale revealed true and false responses. AIDS knowledge score (AKS): to obtain AKS, scores of right answers were summed up. A total of 100 points could be achieved by answering 20 question with 5 points each. Higher scores indicated greater level of knowledge. Third part consisted of questions on having ever sexual intercourse, engaging in sexual intercourse before age 13 years, having four or more life-time sexual partners, condom use during the last encounter; selfassessed knowledge on AIDS with answers like "know very much", "know intermediate level", "know very little" and "know nothing"; the major source of information about AIDS, need a special course on AIDS, integration of course in the curriculum, and course organizing faculty.

\subsection{Item selection and validation}

Questions concerning sexual risk behavior have been selected from the Youth Risk Behavior Surveillance, United States, 1997 Survey [8], and self-assessed knowledge on AIDS/HIV, source of information and need for AIDS course have been retrieved from Petro-Nustas' questionnaire [6]. Questions regarding general knowledge on HIV/AIDS have been adopted and selected from the knowledge, attitudes and belief instrument [9]. Content validity was then assessed by a group of Turkish scholars. A pilot testing of the instrument was carried out on 25 students, who participated in our class in spring 2000 term. The purpose was to detect any unclear, misleading, or highly sensitive questions. This pilot testing helped in finalizing the wording of the questions in the instrument and providing the researcher with a chance of an actual application of the instrument. The student participating in the pilot study were not included in the final sample of this actual study.

\subsection{Statistics}

Student's $t$-test, analysis of variance (ANOVA) and $\chi^{2}$ analysis have been utilized in statistical analysis. Tukey tests has been applied as post-hoc tests for ANOVA analysis,. In all analyses, the usual significance level was 5\%. Statistics have been calculated with Statistica for Windows, Release 4.3 B, Statsoft, 1993.

\section{Results}

The median age of students was 18 years (16-22 years). Six hundred and twenty-one (44\%) female and 806 (56\%) male students participated in this study. All students were going to become university freshmen and the distribution of their schools is as follows: engineering $(n=599,42 \%)$, arts and sciences $(n=300,21 \%)$, economic and administrative sciences $(n=228,16 \%)$, education $(n=186,13 \%)$, architecture $(n=100,7 \%)$. Fourteen $(1 \%)$ did not mention their school. 
Table 1

Number and percentage of students' knowledge about methods of transmission of the HIV virus, general knowledge about AIDS and infected person with HIV virus

\begin{tabular}{|c|c|c|c|c|c|c|}
\hline \multirow[t]{2}{*}{ Statement } & \multicolumn{2}{|l|}{ Correct } & \multicolumn{2}{|l|}{ Incorrect } & \multicolumn{2}{|c|}{ Were undecided } \\
\hline & Percentage & Number & Percentage & Number & Percentage & Number \\
\hline \multicolumn{7}{|l|}{ AIDS can be contracted through: } \\
\hline Sharing food utensils of an infected person & 46 & 656 & 51 & 728 & 3 & 43 \\
\hline Sharing toilet seat of an infected person & 37 & 528 & 59 & 842 & 4 & 57 \\
\hline Sharing injection needle of an infected person & 64 & 913 & 34 & 485 & 2 & 29 \\
\hline Receiving blood from an infected person & 67 & 956 & 33 & 471 & - & - \\
\hline Donating blood & 72 & 1027 & 27 & 385 & 1 & 15 \\
\hline Having sex with infected man & 61 & 870 & 39 & 557 & - & - \\
\hline Having sex with infected woman & 65 & 928 & 35 & 499 & - & - \\
\hline Working with an infected person & 73 & 1042 & 24 & 343 & 3 & 42 \\
\hline Bite of a mosquito & 56 & 799 & 43 & 614 & 1 & 14 \\
\hline Wearing clothes of an infected person & 51 & 728 & 48 & 685 & 1 & 14 \\
\hline Hugging an infected person & 78 & 1113 & 19 & 271 & 3 & 43 \\
\hline Kissing or holding an infected person & 64 & 913 & 35 & 500 & 1 & 14 \\
\hline An infected pregnant woman can infect her unborn baby & 71 & 1013 & 27 & 385 & 2 & 29 \\
\hline Having sex with multiple partners & 79 & 1127 & 21 & 300 & - & - \\
\hline Swimming in the same place where an infected person swims in & 77 & 1099 & 20 & 285 & 3 & 43 \\
\hline Exposure to an infected person who coughs or spits & 59 & 842 & 41 & 585 & - & - \\
\hline \multicolumn{7}{|l|}{ Knowledge } \\
\hline $\begin{array}{l}\text { The infected person with HIV does not usually } \\
\text { show any symptoms of the disease }\end{array}$ & 36 & 514 & 63 & 899 & 1 & 14 \\
\hline ELISA test is the test used to check for the HIV virus in the blood & 65 & 928 & 32 & 457 & 3 & 42 \\
\hline Married people do not get infected with HIV virus & 31 & 442 & 69 & 985 & - & - \\
\hline $\begin{array}{l}\text { A person with AIDS can be totally cured if he } \\
\text { takes the medicine prescribed by the doctor }\end{array}$ & 60 & 856 & 36 & 514 & 4 & 57 \\
\hline
\end{tabular}

Answers on sexual risk behavior indicate that 271 (19\%) participants had had sexual intercourse. Males $(n=208$, $76 \%)$ out-weighted females $(n=63,23 \%)$. No respondent reported engaging in sexual intercourse before age of 13. In addition, $27(10 \%)$ students indicated that they had had four or more sexual partners. Eighty-one (30\%) participants reported condom use during the last encounter (52 (64\%) males and 29 (36\%) females).

To measure self-assessed knowledge, respondents were asked to select one of the four statements that best describes their level of knowledge about AIDS. Seven hundred and twenty-four (51\%) students stated they knew "very much" about AIDS, while 460 (32\%) declared they had an "intermediate" level knowledge, and $243(17 \%)$ said they had "very little" knowledge about AIDS. None stated "knew nothing" about AIDS. No significant differences in selfassessed knowledge between gender has been detected $\left(\chi_{2,1427}^{2}=3.28, P<0.05\right)$. The answers revealed significant differences in relation with the school they attend. Students registered to the faculty of engineering $(n=384,69 \%)$, faculty of economic and administrative sciences $(n=115$, $55 \%)$, and faculty of architecture $(n=42,52 \%)$ declared they knew "very much" on AIDS and had a higher frequency as the faculty of arts and sciences $(n=119,43 \%)$ and the faculty of education $(n=64,40 \%)\left(\chi_{4,724}^{2}=453, P<0.001\right)$.

Television was reported as the major source of information about AIDS $(n=871,61 \%)$. Newspaper and magazines $(n=214,15 \%)$, high school education $(n=143,10 \%)$, friends $(n=128,9 \%)$, parents $(n=43,3 \%)$, and physicians and nurses $(n=29,2 \%)$ were further information sources. The students' general knowledge about AIDS was measured trough their responses to one set of statements, which included 20 questions with related to methods of contracting HIV infection and their general knowledge about persons infected with HIV infection and AIDS disease. Statements (true or false) are shown in Table 1.

Evaluating AKS showed significant differences in relation with the faculty they belong to (Table 2). Students in faculty of education had lower scores than others $\left(F_{4,595}=44.6\right.$, $P=0.01)$.

Table 2

Students' aids knowledge scores: comparison among faculties

\begin{tabular}{lcll}
\hline Faculty & \multirow{2}{*}{$\begin{array}{l}\text { Number of } \\
\text { students }\end{array}$} & \multicolumn{2}{l}{ AIDS knowledge score } \\
\cline { 3 - 4 } & & Mean \pm S.D. & Range \\
\hline Engineering & 599 & $65 \pm 14$ & $35-95$ \\
Arts and sciences & 300 & $50 \pm 15$ & $25-100$ \\
$\begin{array}{l}\text { Economic and } \\
\quad \text { administrative sciences }\end{array}$ & 228 & $72 \pm 14$ & $30-95$ \\
Education & 186 & $43 \pm 17$ & $30-90$ \\
Architecture & 100 & $73 \pm 13$ & $40-95$ \\
Unmentioned & 14 & $57 \pm 15$ & $45-90$ \\
Total & 1427 & $61 \pm 15$ & $25-100$ \\
\hline
\end{tabular}


Finally, the students were asked to indicate whether they need a special course on AIDS as part of their university education curriculum. In a separate question they were asked which faculty should be in charge of these courses. Almost all students $(n=1412,99 \%)$ stated that there should be a course on AIDS in their curriculum. Sixty-three percent $(n=899)$ of the same group said a general health course should be integrated in their curriculum (mandatory and interdisciplinary) which included AIDS as a subtopic. The majority of the students stated that the course should be given by the faculty of education $(n=1200,85 \%)$.

\section{Discussion and conclusion}

\subsection{Discussion}

This study provides descriptive information on university new registrants knowledge of HIV/AIDS. Overall, this study showed strong evidence of a "knowledge deficit problem" regarding students level of information about HIV/AIDS. Although all of the students stated they know what AIDS means, when asked in specific terms, $31 \%$ stated to have intermediate knowledge on HIV/AIDS, and still $17 \%$ had very little knowledge. In a study a low self-assessed level of knowledge on AIDS is mentioned. Ninety-eight percent of university students were aware of AIDS, but $68 \%$ had very little knowledge on AIDS [6]. Further analysis showed, that the knowledge deficit problem was significantly associated with the faculty attended. Therefore, efforts should be given to remove inequalities between faculties.

A significant number of college students aged 18-25 years recognized AIDS as a major social problem and the study stressed the positive role that media plays as a source of information on AIDS. Younger students $(<20$ years) more often reported TV as a source of information, whereas older students reported newspaper as their main resources. Moreover, students of science and humanities faculties preferred $\mathrm{TV}$, more often than medical students as an information source. Senior students reported more often reported newspaper than junior students [6]. Brook supported this and found television (93\%); and newspaper and periodicals (90\%) as the principal source of knowledge on AIDS [10]. These findings are consistent with ours. Schools, parents and health professionals are secondary sources for information and should be more involved in AIDS education.

Students' relative "knowledge deficit" was not only apparent in their responses to self-assessed knowledge section, but also to statements assessing their knowledge about AIDS disease (Table 1). Although the mean score of the students was 60 (of 100), there were still students who received low points on this 20 -item instrument. Students belonging to the faculty of education scored lower. PetroNustas also found in her study differences between faculties. Students in the faculties of humanities and science were less knowledgeable than medical students [6]. But no difference was detected in other faculties, showing a even distribution of knowledge between university freshmen.

In our study there was no significant difference of sexual risk behaviors across different faculties. The relatively low rate of condom use in both genders, particularly needs to be addressed by educational activities. Although, the findings on sexual risk behavior are lower than the most recent national Youth Risk Behavior Surveillance Survey, each student deserves education because information regarding the transmission and prevention of HIV/AIDS is necessary prerequisite of risk-reduction behavior [11].

\subsection{Conclusion}

There is a considerable rationale to include a special course on HIV/AIDS as a part of the curriculum at university. Educational advisors, physicians and nurses should discuss with students on prevention HIV contamination.

\subsection{Implication practice}

The result of this study suggests a special course on HIV/ AIDS as a part of their curriculum. Educational programs are most effective in well-defined audiences which have demand for help, and success in AIDS education is best assured when education is carried out on continuous and long-range strategies with realistic objectives $[6,12]$. The study strongly recommends faculties at Middle East Technical University (METU) should integrate an AIDS course in their curricula.

Although the results of this study are limited, in that they are applied only to new registrant enrolled to METU, they indicate the need for further examination of students' knowledge about HIV/AIDS on the universities. The significance of this knowledge assessment study is that it was administered in one of the largest sample of university students in Turkey and no further studies on this subject originating from Turkey exist for international comparison.

\section{Acknowledgements}

This paper has been presented at the EGPRW Tampere Meeting, Spring 2001.

\section{References}

[1] Tümer A, Ünal S. Epidemiology of HIV infection in the World and in Turkey. In: Ünal S, editor. AIDS: modern medical seminars. Ankara: Günes Publishers; 2000. p. 1-10 [in Turkish].

[2] Turkish Health Ministry. Data of General Directorate of Primary Health Care. Ankara: Turkish Health Ministry; 2000.

[3] Duyan V, Agalar F, Sayek I. Surgeons' attitudes toward HIV/AIDS in Turkey. AIDS Care 2001;13:243-50.

[4] Baser Z. The fight against HIV/AIDS in Turkey. In: Ünal S, editor. AIDS: modern medical seminars. Ankara: Günes Publishers; 2000. p. 64-73 [in Turkish]. 
[5] Aral SO, Fransen L. STD/HIV prevention in Turkey. Planning a sequence of intervention. AIDS Educ Prev 1995;7:544-53.

[6] Petro-Nustas W. University students' knowledge of AIDS. Int J Nurs Stud 2000;37:423-33.

[7] Bellingam K, Gilles P. Evaluation of an AIDS education program for young adults. J Epidemiol Community Health 1993;47:1345.

[8] Karin L, Kinchen SA, Williams BI, et al. Youth Risk Behavior Surveillance, United States, 1997. In: Centers for Disease Control Surveillance summaries; MMWR 1998;47(SS-3):1-89.
[9] Kulwicki A, Cass P. An assessment of Arab American knowledge, attitudes, and beliefs about AIDS. Image 1994;26:13-7.

[10] Brook U. AIDS-related knowledge and attitude of high school students in Holon. Isr J Trop Pediatr 1993;39:382-4.

[11] Boyer CB, Shafer MA, Wibbelsman CJ, Seeberg D, Teitle E, Lovell N. Association of sociodemographic, psychosocial, and behavioral factors with sexual risk and sexually transmitted diseases in teen clinic patients. J Adolesc Health 2000;27:102-11.

[12] Brook U. AIDS knowledge and attitudes of pupils attending urban high schools in Israel. Patient Educ Couns 1999;36:271-8. 